\title{
Within-city Variation in Urban Decline: The Case of Detroit
}

\author{
By Veronica Guerrieri, DANIEl Hartley, AND ERIK HuRsT**
}

\begin{abstract}
* Guerrieri: University of Chicago Booth School of Business, 5807 S. Woodlawn Avenue, Chicago, IL 60637 (email: Veronica.Guerrieri@ChicagoBooth.edu). Hartley: Federal Reserve Bank of Cleveland, PO Box 6387, Cleveland, OH 44101 (email: Daniel.Hartley@clev.frb.org) Hurst: University of Chicago Booth School of Business, 5807 S. Woodlawn Avenue, Chicago, IL 60637 (email: Erik.Hurst@ChicagoBooth.edu). Guerrieri and Hurst would like to acknowledge financial support from the University of Chicago's Booth School of Business. The views expressed herein are those of the authors and do not necessarily reflect the position of the Federal Reserve Bank of Cleveland or the Federal Reserve System.
\end{abstract}

When a city experiences a decline in either income or population, do all neighborhoods within the city decline equally? Or, do some neighborhoods within the city decline more than others? If so, what are the characteristics of the neighborhoods that decline the most? In this paper, we provide some answers to these questions by looking at what happened to different types of neighborhoods within the city of Detroit as Detroit experienced a sharp decline in average income and population from the 1980s to the late 2000s. The large declines in population and average income during this period relative to other large cities make Detroit a natural candidate to study the within-city properties of urban decline.

We view our analysis through the recently developed model of Guerrieri, Hartley and Hurst (2011). In that model, individuals are endowed with either high or low income and all individuals have a preference for living around richer neighbors. This is a short hand way to model individuals having preferences for amenities that are endogenously provided when neighborhood income rises (such as lower crime, more entertainment and service amenities, peer effects in schooling, etc.). ${ }^{1}$

\footnotetext{
1 Recent work that finds strong support for such preferences include Bayer et al. (2007) and Rossi-Hansberg et al. (2010).
}

Under relatively general assumptions, the model yields an equilibrium in which residents sort by income. Land prices are highest in the rich neighborhoods because of the higher consumption externality and decline as the distance from the rich neighborhoods increases. A key prediction of this model is that in response to a positive population or income shock at the city level, the new influx of richer residents will choose to locate in the poorer neighborhoods that border the richer neighborhoods so as to maximize their consumption of the positive neighborhood amenities. In Guerrieri, Hartley, and Hurst (2011), we refer to this process as endogenous gentrification. We then provide a variety of evidence showing that in response to positive city-wide labor demand shocks that lead to an influx of richer residents, the poor neighborhoods that border the rich neighborhoods experience the greatest increase in housing prices within the city and they do so because the neighborhood gentrifies (poor residents exit and richer residents migrate in).

The innovation in this paper is to show that the process also holds in reverse. When a city experiences an extended period of the outmigration of residents, the model of Guerrieri, Hartley and Hurst (2011) predicts the following: (1) the population declines should be the largest in the ex-ante poorest neighborhoods and smallest in the ex-ante richest neighborhoods, (2) the income declines should be greatest in ex-ante richest neighborhoods and smallest in the ex-ante poorest neighborhoods, and (3) housing prices in some neighborhoods would be lower than they would be otherwise because of the declining amenities in those neighborhoods 
that result from the influx of poor residents. ${ }^{2}$ As we show below, the first of these two predictions are definitely born out in the Detroit data during the 1980 to the late 2000s period. Given the nature of the house price data, it is hard to definitely say whether the patterns in the house price changes across neighborhoods are consistent with the endogenous changing amenity story. However, as we show, the patterns in house price movements across Detroit neighborhoods are very different than the patterns within other large U.S. cities during the same time period.

Before proceeding, it is worth mentioning why such an analysis is of interest to economists. Recently, many papers have explored the welfare implications of differential city-wide demand shocks across U.S. cities. ${ }^{3}$ One implication of these theories is that poor residents can be made partially better off after a negative city-wide labor demand shock because of the cheaper housing stock. The intuition being that rich residents are found to be more likely to migrate out of the city after the negative city-wide labor demand shock. The out-migration of the richer residents puts downward pressure on housing prices in the city partially making the remaining poorer residents better off. However, researchers making such welfare calculations almost always assume that none of the decline in housing prices at the city level in response to a negative city wide labor demand shock is due to declining amenities in the city. ${ }^{4} \quad$ As we show, however, that assumption seems to be strongly violated in the data. Part of the reason house prices are low in cities that face a negative labor demand shock is that the out-migration of richer residents make the city as a whole a less

\footnotetext{
2 For a full formulization of these predictions, see Guerrieri, Hartley and Hurst (2011).

3 See, for example, Moretti (2008) and Notowidigdo (2011).

4 One recent exception is Diamond (2011).
}

desirable place to live. Such an endogenous change in amenities needs to be accounted for when calculating changes in the welfare of different groups associated with changing house prices in response to local labor demand shocks.

\section{The Decline of Detroit}

Table 1 compares the trends in income, house prices, population, and other demographics between the city Detroit and two comparison samples. ${ }^{5}$ The first comparison sample is the city of Chicago. We pick Chicago because it another large midwestern city that had a similar income and demographic composition in 1980 . The second comparison sample is a composite of the other U.S. cities that had the largest population in 1970s. Along with Detroit, the other U.S. cities that rounded out the top five with respect to population in 1970 s were New York, Chicago, Los Angeles, and Philadelphia. ${ }^{6}$ All data in Table 1 comes from the IPUMS samples and all variables are reported in real year 2000 dollars. $^{7}$ The 1980 data comes from the U.S. Census. The pooled 2005-2009 data comes from the American Community Survey. Lastly, we want to stress that our analysis is at the city level and not at the broader MSA level.

\section{[ Insert Table 1 Here]}

A few things are noticeable from Table 1. First, with respect to median household income in 1980, Detroit was similar to both Chicago and the broader comparison set of

Some researchers have documented that the population, demographic, and income patterns in Detroit differ from other large cities during the last few decades. See, for example, Glaeser and Ponzetto (2007).

6 In the 1970 Census, Detroit was the fifth largest city and Houston was sixth. In the 1980 Census, Houston was fifth and Detroit was sixth. Given the data restrictions in the next part of our analysis, we did not include Houston in our comparison sample.

${ }^{7}$ http://usa.ipums.org/usa/ 
cities. Specifically, median household income in 1980 was roughly $\$ 35,000$, $\$ 30,000$, and $\$ 34,000$, respectively, in Detroit, Chicago, and the broader set of comparison cities. The income distribution (25th and 75th percentile) in 1980 was very similar between Detroit and the comparison samples.

Second, relative to the comparison cities, Detroit's population plummeted between 1980 and the late 2000s. During that time period, the city of Detroit lost 24 percent of its population. During the same time period, Chicago's population fell by only 6.6 percent. The population in the broader set of comparison cities actually increased by 11.5 percent during this time period. All of the increase was driven by New York and LA. Like Chicago, Philadelphia's population fell slightly.

The third fact to notice from Table 1 is that as the population fell in Detroit relative to other cities, Detroit was becoming poorer relative to other cities. Specifically, between 1980 and the late 2000s household income in Detroit fell by 24 percent while median household income increased by roughly 16 percent in Chicago and increased by 29 percent in the broader set of comparison cities. Consistent with the income data, the change in educational attainment in Detroit during this period was much smaller than the comparison cities. In the late 2000 s, only 12 percent of Detroit residences over the age of 25 had a Bachelor's degree. The comparable number in the comparison cities was over 30 percent. The final fact about Detroit during this time period is that median house values increased by only 60 percent (in real terms) during the three decades after 1980. The comparable increases in Chicago and the comparison cities were 136 percent and 250 percent, respectively.

In summary, Table 1 shows that during the last three decades Detroit experienced a dramatic decline in population, became relatively poorer in terms of income and educational attainment, and had relatively stagnant house prices as compared with other large U.S. cities. As a result, Detroit becomes a natural candidate to explore within-city patterns of urban decline. We turn to that analysis in the next section.

\section{Neighborhood Income, Demographic, and Housing Price Changes Across Detroit Census Tracts}

Our unit of analysis is census tracts within the city when exploring within-city changes in population, income, demographics, and housing prices. We use the tabulated data from the 1980 Census (from the Neighborhood Change Database) for our initial period observations on census tracks. We use the tabulated data at the census tract level from the 2005 - 2009 American Community Survey (ACS) for our ending period observations. Our sample for Detroit consists of the 207 city of Detroit census tracts where the boundaries of the census tracts remained constant or changed only slightly between 1980 and $2009 .^{8}$ Additionally, all census tracts in our sample had to have nonmissing tabulated values for median house prices, income, and key demographic variables within both the 1980 Neighborhood Change Database and the 2005-2009 ACS. $^{9}$

\footnotetext{
${ }^{8}$ We include 10 tracts whose centroid has moved less than 100 meters and whose area has changed by less than a 200 meter by 200 meter area (smaller than a Chicago city block).

${ }^{9}$ The city of Detroit currently has a total of 313 census tracts. Our sample includes less than the current universe of Detroit census tracts because we are restricting the sample to only include census tracts that didn't change their boundaries since 1980. The census tracts excluded from our sample do not appear to be systematically different along income and demographic variables relative to the census tracts included in our sample. Given this restriction, the total population for the census tracts in our analysis sample for Tables 2, 3 and 4 are less than the total population for the city as a whole. See the online Data Appendix that accompanies this paper for a full discussion of the sample criteria as
} 
As above, we use as comparison groups the census tracts in the city of Chicago and the census tracts within New York, Los Angeles, Chicago, and Philadelphia. For these comparison groups we make the similar sample restrictions in that the census tract had to have a constant or only slightly changed border between 1980 and 2009 and had to have non-missing tabulated values for the key variables of interest.

We begin by segmenting the census tracts in each of the cities by their initial median house value in $1980 .{ }^{10}$ Specifically, we divide the census tracts into ten groupings each representing their decile in the 1980 median housing price distribution. As a result, for our Detroit sample, each decile has roughly 21 census tracts in it. Decile 1 includes the census tracts with the lowest housing prices. Decile 10 includes the census tracts with the highest housing prices. We hold these deciles fixed throughout all of our analysis in Tables 2, 3, and 5. When computing decile averages of variables of interest we weight the census tracts by either the population in the census tract (for the results in Tables 2, 3, and 4) or by the number of owner-occupied residents in the census tract (for the results in Table 5). The results in Table 5 examine median house values across the deciles.

Table 2 tests two of the predictions of Guerrieri, Hurst and Hartley (2011) for cities experiencing a negative labor demand shock that causes an outflow of residents. First, the model predicts that population should decline most in the poor neighborhoods relative to the richer neighborhoods. This is because the city should be contracting and people want to locate as close to the richer neighborhoods as possible given the higher externalities from those neighborhoods. Second, the model

well as the comparison of included and excluded census tracts in our analysis.

${ }^{10}$ Results are very similar if we segmented the census tracts by their initial median household income. We chose to segment the census tracts by initial housing price to provide consistency with what we did in Guerrieri, Hartley, and Hurst (2011). predicts that the income declines should be greatest in the neighborhoods that were initially close to the rich neighborhoods. This is because the rich neighborhoods will contract. The neighborhoods that used to be the fringe rich neighborhoods will now be populated by poorer residents. As a result, we should observe disproportionately large declines in income in these neighborhoods as they flip from being higher income to being lower income. The results in Table 2 show exactly these patterns.

[ Insert Table 2 Here]

In panel $A$ of Table 2, we show the percentage change in population by initial within-city house price decile for Detroit, Chicago, and a simple average across New York, Chicago, Los Angeles, and Philadelphia. The first thing to notice is that the population changes were not the same across the ten deciles in Detroit based on 1980 housing prices. It should be noted that the initial population in each of these deciles were nearly identical because of the way we created the deciles. In the poorer deciles (deciles 14), population fell by between roughly 30 and 40 percent. In the middle deciles (deciles 58 ), population fell by between 10 and 15 percent. The population in the top 2 deciles (deciles 9 and 10), however, remained roughly constant. The differences in the change in population across the three groupings were statistically significant at the 1 percent level. ${ }^{11}$ As the city contracted, it lost most of the population from the initially poor neighborhoods. The city contracted in toward the initial rich neighborhoods. It should be noted that Chicago also lost some population from its initially poor neighborhoods.

\footnotetext{
11 The difference in means between population growth in deciles 1-4 and deciles 5-8 was -0.23 with a standard error of 0.04 . The difference in means between deciles $1-4$ to deciles 9-10 was -0.34 , standard error 0.6. The difference in means between deciles 5-8 to deciles $9-10$ was -0.12 , standard error 0.4.
} 
However, the richer deciles in Chicago actually experienced relatively large gains in population.

The decline in income within Detroit was concentrated among deciles 5-9. Within these deciles, household median income fell by roughly 25 percent. In deciles 1-4, median income fell by roughly 15 percent. The difference in the change in income between deciles 1-4 (pooled) and deciles 5-9 (pooled) was statistically significant at the 1 percent level. Household income in decile 10 (the richest decile) actually remained roughly constant over the 30 year period. For reference, it should be noted that household income increased monotonically throughout the deciles in 1980. For example, in 1980, median household income in deciles $1,3,5,6$, 8 and 10 were, respectively, $\$ 20,200, \$ 23,400$, $\$ 31,000, \$ 34,000, \$ 40,000$, and $\$ 44,900$. In the late 2000s, average median household income in deciles 1 through 7 were all between $\$ 19,000$ and $\$ 23,000$. In other words, most of the deciles in Detroit in the late 2000s were substitutable with one another at very low levels of income. The formerly richer deciles became poorer despite the relatively stable population patterns. This is consistent with theory of endogenous gentrification (albeit in reverse) outlined in Guerrieri, Hartley, and Hurst (2011).

A few additional things are worth pointing out. First, the patterns of income growth across the deciles in Chicago and the broader set of comparison cities display a strikingly different pattern. In particular, there was large across-the-board income growth throughout the deciles. Second, for the comparison cities, it was the poorest and the richest deciles that saw the largest income growth. As we documented in Guerrieri, Hartley, and Hurst (2011) much of these two patterns can be explained by areas of those census tracts gentrifying. Some of the poorest neighborhoods were the neighborhoods that were bordering the richest neighborhoods.
Finally, as seen in Table 3, other demographic variables display similar patterns as household income. In particular, within Detroit, the relatively rich neighborhoods experienced a larger influx of Black residents, a larger decline in homeownership rates, and a relatively large increase in the poverty rate. All the results point to the fact that the formerly rich neighborhoods in Detroit experienced a large influx of poorer residents as Detroit declined. So, despite the population in these neighborhoods remaining relatively constant, the composition of these neighborhoods changed dramatically. To the extent that the composition of neighborhoods partially determines house prices, part of the movement in house prices for Detroit as a whole or for individual neighborhoods within Detroit will be a reflection of changing amenities.

\section{[ Insert Table 3 Here]}

Before looking at housing prices across the neighborhoods within Detroit, we wish to test one other prediction of the Guerrieri, Hartley, and Hurst (2011) model. Their model predicts that it is the neighborhoods that border the richest neighborhoods that should decline the most as the city experiences a large decline in population. In what we showed above, we explored the relationship of income declines across initial house price deciles. In Table 4, we report the results of a regression of census tract income growth on the log distance from that census tract to the nearest census tract that is in the top 1980 decile and the census tract log median household income in 1980. We restrict our sample to include only those census tracts in deciles 7-9 (in the upper range of the initial house price distribution). As seen from Table 4, it is the census tracts that are closest to the richest census tracts within Detroit in 1980 that experience the largest declines in income between 1980 and the late 2000s. Census tracts that were 1 mile from 
the richest census tracts experienced about an 11 percentage point larger decline in median household income relative to census tracts that were 4 miles from the richest census tracts ($0.055 * 2$ ). These formerly rich neighborhoods changed to poor neighborhoods as the city contracted. In contrast, in Chicago, distance to the nearest top decile census tract does not explain income growth among the upper range of the initial house price distribution (deciles 7-9).

\section{[ Insert Table 4 Here]}

Table 5 shows the changes in median house prices for census tracts based on the deciles of within-city 1980 housing prices for Detroit, Chicago, and the broader set of comparison cities. As with Tables 2 and 3, we provide the four city average when reporting the results from the broader set of comparison cities. Unlike Tables 2 and 3, we aggregate some of the deciles together for the housing price table to mitigate some of the noise across the individual deciles. The increased noise is due to the fact that we only have house prices for homeowners and the homeownership rate is much lower in Detroit than in other cities. To this end, we combine deciles 1 and 2, deciles 3-5, deciles 6-8, and deciles 9 and 10. With respect to housing price growth, we simply report the change in median house prices within the census tracts in the combination of deciles (weighting by the number of homeowners in the Census tract). In panel A, we do not hedonically adjust for the changing quality of the housing stock in the census tracts over time. In panel $B$, we do hedonically adjust for the changing quality of the housing stock in the census tracts over time. $^{12}$

\footnotetext{
12 To adjust for changes in structure quality within census tracts over time, we regress housing price growth on the change in the fraction of single family detached housing units, the change in the fraction of studio and one bedroom units, the change in the fraction of two bedroom units, the change in the fraction of 3 bedroom units, the
}

\section{[ Insert Table 5 Here]}

As seen from the Table 5, poor neighborhoods appreciated much more extensively in Chicago and the broader set of comparison cities than richer neighborhoods. This fact was extensively documented in Guerrieri, Hartley, and Hurst (2011). Part of this was due to the gentrifying of poorer neighborhoods as Chicago and the broader set of comparison cities got richer during the 1980s, 1990s, and 2000s. In Detroit, however, the housing appreciation rates were nearly identical across the different deciles (after adjusting for hedonic differences). So despite the differential patterns across census tracts with respect to population and income, the changes in house prices are, if anything, slightly smaller in the poor neighborhoods (after adjusting for the changing difference in the quality of housing stock during the period). How much of these effects are driven by changing amenities in the city as a whole or in the individual neighborhoods? It is hard to tell from this analysis. The reason is that the large decline in population in the poor neighborhoods is putting downward pressure on the housing prices in these neighborhoods. Likewise, the declining amenities in the richer neighborhoods is putting downward pressure on the house prices in these neighborhoods. The net effect of the two factors make it hard to tease out the effect of declining neighborhood amenities on house prices within Detroit. The take away from Table 5 is that (1) there is not much difference in house price appreciation rates across rich and poor neighborhoods within Detroit during the last 30 years and (2) the patterns for Detroit with respect to within city

change in the fraction of units built in the past 5 years, the change in the fraction of units built 5-20 years ago, and the change in the fraction of units built 20-40 years ago. We then add the constant from this regression to the residuals, thus zeroing out changes in structure quality. In Guerrieri, Hartley, and Hurst (2011), we show that the hedonically adjusted housing price growth at the zip code level is highly correlated with the corresponding zip code level repeat sales price indices from Case Shiller when the samples overlap. 
house price growth looks different than the patterns within the comparison set of cities.

\section{Conclusion}

In this paper, we have shown that there are important within-city dynamics that occur when a city experiences a prolonged period of population decline. In particular, the patterns of population and income movement are represented well by the model of endogenous gentrification put forth by Guerrieri, Hartley, and Hurst (2011). As a city experiences a large outmigration of population, the remaining residents should want to locate nearer to richer residents so as to maximize their consumption of endogenously provided neighborhood amenities (lower crime, increased entertainment and service amenities, etc.). Such patterns are found within Detroit during the last three decades. The declines in population and income were not experienced uniformly across the census tracts within Detroit. The poorest census tracts experienced the largest declines in population while it was the richer census tracts that experienced the largest declines in income. In particular, it was the relatively rich neighborhoods that were in close proximity to the richest neighborhoods that experienced the biggest income declines. These border neighborhoods are the most elastic with respect to changes in neighborhood composition in response to city wide labor demand shocks.

The paper extends the work in Guerrieri, Hartley, and Hurst (2011) by examining what happens to the sorting patterns of people, income and house prices within a city that is experiencing a dramatic decline in population. The results of this paper and Guerrieri, Hartley, and Hurst (2011) suggest that researchers need to take seriously how amenities may be changing within cities in response to local labor demand shocks. As rich residents move in or rich residents move out, the nature of city-wide amenities can change if people have preferences for living around richer residents. The within-city movements of people during booms and busts as well as the detailed work on house price dynamics shown in Guerrieri, Hartley and Hurst (2011) suggest that these factors are important to consider when thinking about the welfare impacts of local labor demand shocks.

\section{REFERENCES}

Bayer, Patrick, Robert McMillan, and Fernando Ferreira. 2007. "A Unified Framework for Measuring Preferences for Schools and Neighborhoods" Journal of Political Economy, 115 (4), 588-638.

Diamond, Rebecca. 2011. "The Welfare Implications of Changes in Local Wages, Prices, and Amenities across U.S. Cities: 1980-2000". Harvard University mimeo.

Glaeser, Edward and Giacomo Ponzetto. 2007. "Did the Death of Distance Hurt Detroit and Help New York?" NBER Working Paper 13710.

Guerrieri, Veronica, Daniel Hartley, and Erik Hurst. 2011. "Endogenous Gentrification and Housing Price Dynamics" University of Chicago mimeo.

Moretti, Enrico. 2008. "Real Wage Inequality" NBER Working Paper 14370.

Notowidigdo, Matthew. 2011. "The Incidence of Local Labor Demand Shocks". NBER Working Paper 17167.

Rossi-Hansberg, Esteban, Pierre-Daniel Sartre, and Raymond Owens III. 2010. "Housing Externalities" Journal of Political Economy, 118(3), 485-535. 
TABLE 1 - COMPARISON OF INCOME, HOUSE PRICES, POPULATION, AND DEMOGRAPHICS OF DETROIT AND OTHER LARGE U.S. CITIES IN 1980 AND 2005/2009

\begin{tabular}{|c|c|c|c|c|c|c|c|c|c|}
\hline \multirow[b]{2}{*}{ Variables } & \multicolumn{3}{|l|}{ Detroit } & \multicolumn{3}{|l|}{ Chicago } & \multicolumn{3}{|c|}{$\begin{array}{l}\text { Chicago, New York, Los Angeles, and } \\
\text { Philadelphia }\end{array}$} \\
\hline & 1980 & $\begin{array}{l}2005- \\
9\end{array}$ & Growth & 1980 & $2005-9$ & Growth & 1980 & $2005-9$ & Growth \\
\hline \multicolumn{10}{|l|}{ Income } \\
\hline Median & 34,999 & 26,671 & -23.8 & 36,198 & 42,081 & 16.3 & 33,999 & 43,850 & 29.0 \\
\hline $25^{\text {th }}$ Percentile & 16,120 & 12,714 & -21.1 & 17,899 & 20,376 & 13.8 & 17,000 & 21,261 & 25.1 \\
\hline $75^{\text {th }}$ Percentile & 55,996 & 49,244 & -12.1 & 57,995 & 73,770 & 27.2 & 55,986 & 78,535 & 40.3 \\
\hline \multicolumn{10}{|l|}{ House Price (Census) } \\
\hline Median & 42,474 & 69,279 & 63.1 & 94,943 & 224,138 & 136.1 & 104,937 & 366,771 & 249.5 \\
\hline $25^{\text {th }}$ Percentile & 32,480 & 52,978 & 63.1 & 64,961 & 152,821 & 135.3 & 64,961 & 183,386 & 182.3 \\
\hline $75^{\text {th }}$ Percentile & 57,465 & 91,693 & 59.6 & 124,925 & 285,267 & 128.4 & 169,897 & 509,405 & 199.8 \\
\hline Population & $1.2 \mathrm{M}$ & $9.2 \mathrm{M}$ & -24.0 & $3.0 \mathrm{M}$ & $2.8 \mathrm{M}$ & -6.6 & $14.8 \mathrm{M}$ & $16.5 \mathrm{M}$ & 11.5 \\
\hline \multicolumn{10}{|l|}{ Percent With Bachelor } \\
\hline Degree & 8.3 & 12.1 & 46.1 & 13.8 & 32.0 & 131.6 & 16.4 & 31.1 & 89.5 \\
\hline Percent Black & 63.0 & 77.6 & 23.1 & 39.9 & 34.1 & -14.7 & 28.1 & 24.8 & -11.9 \\
\hline Home Ownership Rate & 41.5 & 44.3 & 6.7 & 59.3 & 51.4 & -13.3 & 65.0 & 60.1 & -7.6 \\
\hline
\end{tabular}

Notes: Tabble shows income and demographic statistics for the city of Detroit, the city of Chicago, and the pooled cities of New York, Los Angeles, Chicago, and Philadelphia. All data comes from the IPUMS dataset. The 1980 data is from the U.S. Census. The 2005-2009 data is from the pooled American Community Survey. All dollar values are in 2000 dollars. The growth columns refer to the growth between 1980 and the 2005-2009 pooled samples. 
TABLE 2 - 1980-2005/2009 CHANGES IN WITHIN CITY POPULATION AND HOUSEHOLD INCOME,

BY 1980 NEIGHBORHOOD HOUSE PRICE DECILES

\begin{tabular}{lllllll}
\hline \hline & \multicolumn{3}{l}{$\begin{array}{l}\text { A. 1980-2005/2009 Percent Growth in } \\
\text { Population }\end{array}$} & \multicolumn{2}{l}{$\begin{array}{l}\text { B. 1980-2005/2009 Percent Growth in } \\
\text { Median Household Income }\end{array}$} \\
\cline { 2 - 7 } $\begin{array}{l}\text { 1980 House Price } \\
\text { Decile }\end{array}$ & Detroit & Chicago & $\begin{array}{l}\text { Average Across Broad Set of } \\
\text { Comparison Cities }\end{array}$ & Detroit & Chicago & $\begin{array}{l}\text { Average Across Broad Set of } \\
\text { Comparison Cities }\end{array}$ \\
\hline & & & & & & \\
1 & -35.7 & -23.4 & 1.2 & -13.7 & 61.0 & 42.6 \\
2 & -34.2 & -22.0 & -2.1 & -13.8 & 30.4 & 31.0 \\
3 & -27.4 & -28.2 & 0.0 & -13.7 & 11.8 & 23.0 \\
4 & -38.2 & -20.0 & 1.9 & -18.6 & 12.3 & 19.0 \\
5 & -15.1 & -7.4 & 9.8 & -27.0 & 24.5 & 25.2 \\
6 & -12.9 & -9.8 & 10.9 & -28.5 & 4.2 & 20.5 \\
7 & -7.4 & 4.9 & 10.9 & -26.8 & 14.1 & 21.3 \\
8 & -11.6 & 10.7 & 11.1 & -22.1 & 24.8 & 34.1 \\
9 & -4.0 & 9.3 & 10.2 & -23.4 & 34.8 & 37.8 \\
10 & 1.1 & 4.8 & 5.5 & -4.3 & 39.5 & 52.3 \\
& & & & & & \\
\hline
\end{tabular}

Notes: Table shows the growth rate in population (panel A) and median household income (panel B) for Detroit, Chicago, and our broad comparison set of cities (which includes New York, Los Angeles, Chicago, and Philadelphia) across different within-city deciles of house prices in 1980. The level of analysis is within-city census tracts. Deciles are made by ranking census tracts by their median house value in 1980 . Roughly one-tenth of all census tracts are in each decile. Decile 1 includes the census tracts with the lowest house prices in 1980 . To compute the growth rates, we calculate the population (panel A) or income (panel B) for 1980 and the 2005-2009 period separately by averaging over the census tracts in the decile. When averaging over the census tracts in a given year within each decile, we weight by the number of people in the census tracts. See the text for sample restrictions. For the average across the broad set of comparison cities, we compute the growth rate in population (or income) in each decile separately for each city and then take the simple average over the four cities. 
TABLE 3 - 1980-2005/2009 CHANGES IN Within CiTY PERCENT BLACK, HOMEOWNERSHIP RATE, AND POVERTY RATE, BY 1980 NEIGHBORHOOD HOUSE PRICE DECILES

\begin{tabular}{|c|c|c|c|c|c|c|c|c|c|}
\hline \multirow[b]{2}{*}{$\begin{array}{l}1980 \\
\text { House } \\
\text { Price } \\
\text { Decile }\end{array}$} & \multicolumn{3}{|c|}{$\begin{array}{l}\text { A. } 1980-2005 / 2009 \text { Percentage Point } \\
\text { Change in Percent Black }\end{array}$} & \multicolumn{3}{|c|}{$\begin{array}{l}\text { B. } 1980-2005 / 2009 \text { Percentage Point } \\
\text { Change in Homeownership Rate }\end{array}$} & \multicolumn{3}{|c|}{$\begin{array}{l}\text { C. } 1980-2005 / 2009 \text { Percentage Point } \\
\text { Change in Poverty Rate }\end{array}$} \\
\hline & Detroit & Chicago & $\begin{array}{l}\text { Average Across } \\
\text { Broad Set of } \\
\text { Comparison Cities }\end{array}$ & Detroit & Chicago & $\begin{array}{l}\text { Average Across } \\
\text { Broad Set of } \\
\text { Comparison Cities }\end{array}$ & Detroit & Chicago & $\begin{array}{l}\text { Average Across } \\
\text { Broad Set of } \\
\text { Comparison Cities }\end{array}$ \\
\hline 1 & 4.2 & 1.0 & -14.4 & -0.9 & 12.2 & 5.1 & 20.0 & -3.2 & -3.5 \\
\hline 2 & 9.6 & 3.1 & -5.9 & 3.0 & 8.1 & 0.9 & 16.1 & 1.3 & 0.7 \\
\hline 3 & 14.1 & 2.8 & 0.6 & -4.3 & 3.0 & -1.8 & 14.4 & 3.7 & 2.5 \\
\hline 4 & 11.3 & 3.7 & 4.7 & -6.9 & 2.9 & -1.2 & 13.3 & 5.5 & 4.0 \\
\hline 5 & 31.2 & 2.9 & 6.3 & -15.0 & 5.2 & -0.4 & 18.6 & 2.9 & 3.0 \\
\hline 6 & 35.1 & 6.0 & 7.5 & -14.3 & 0.5 & -0.8 & 19.6 & 7.4 & 4.6 \\
\hline 7 & 31.8 & 7.2 & 8.7 & -11.2 & 3.1 & 0.5 & 19.9 & 4.6 & 4.1 \\
\hline 8 & 20.8 & 9.8 & 5.1 & -10.0 & 6.0 & 2.4 & 11.9 & 4.1 & 2.5 \\
\hline 9 & 41.3 & 4.2 & 3.1 & -10.1 & 7.8 & 5.3 & 13.9 & 4.0 & 1.8 \\
\hline 10 & 31.2 & -0.5 & 0.2 & 1.1 & 13.1 & 11.5 & 6.2 & 2.4 & 0.1 \\
\hline
\end{tabular}

Notes: See the note to Table 2 for how the deciles were computed. Aside from exploring the percentage point change in percent black (panel A), the percentage point change in the homeownership rate (panel B), and the percentage point change in the poverty rate (panel C), the table is analogous in setup and sample as Table 2 . 
TABLE 4 -RELATIONSHIP BETWEEN GROWTH IN INCOME BETWEEN 1980 AND 2005/2009 AT CENSUS TRACT LEVEL AND DISTANCE

TO RICH NEIGHBORHOODS

\begin{tabular}{lll}
\hline \hline Independent Variable & Detroit & Chicago \\
\hline & & \\
Log Distance from Census Tract to Nearest Census & -0.055 & 0.017 \\
Tract in the Top Decile of Housing Prices in 1980 & $(0.026)$ & $(0.062)$ \\
& & \\
Log Median Household Income in 1980 & -0.145 & -1.421 \\
& $(0.061)$ & $(0.428)$ \\
Number of Observations & 61 & 235 \\
R-squared & 0.121 & 0.275 \\
& & \\
\hline
\end{tabular}

Notes: Table reports the simple regression of percent change in income growth within the census tract between 1980 and the pooled $2005-2009$ sample on the log distance of that census tract to the nearest census tract in the top housing price decile in 1980 and the log of median household income in 1980. The level of observation is the census tract. We only include observations from deciles 7-9 in the regression. Among relatively richer deciles in 1980, we are asking how the change in income in that decile is related to the distance to the nearest census tract in the top housing price decile. The regression is weighted by population in 1980. Robust standard errors in parenthesis. 
TABLE 5-1980-2005/2009 PERCENT CHANGE IN WITHIN CITY HOUSE PRICE GROWTH, BY 1980 NEIGHBORHOOD HOUSE PRICE DECILES

\begin{tabular}{|c|c|c|c|c|c|c|}
\hline \multirow[b]{2}{*}{$\begin{array}{l}1980 \text { House } \\
\text { Price Pooled Deciles }\end{array}$} & \multicolumn{3}{|c|}{$\begin{array}{l}\text { A. 1980-2005/2009 Percent Growth in } \\
\text { House Prices (No Hedonic Adjustments) }\end{array}$} & \multicolumn{3}{|c|}{$\begin{array}{l}\text { B. 1980-2005/2009 Percent Growth in } \\
\text { House Prices (With Hedonic Adjustments) }\end{array}$} \\
\hline & Detroit & Chicago & $\begin{array}{l}\text { Average Across Broad } \\
\text { Set of Comparison Cities }\end{array}$ & Detroit & Chicago & $\begin{array}{l}\text { Average Across Broad } \\
\text { Set of Comparison Cities }\end{array}$ \\
\hline 1 and 2 & 93.8 & 394.4 & 374.0 & 108.0 & 362.0 & 366.8 \\
\hline 3,4 , and 5 & 60.0 & 186.7 & 207.6 & 107.8 & 195.6 & 229.9 \\
\hline 6,7, and 8 & 56.1 & 113.2 & 155.1 & 129.1 & 167.1 & 211.6 \\
\hline 9 and 10 & 53.0 & 82.3 & 121.2 & 121.9 & 156.8 & 189.7 \\
\hline
\end{tabular}

Notes: This table is analogous to Tables 2 and 3 except the variable of interest is the percent growth in median house prices. See the note to Table 2 for a more detailed description of the table set up and samples used. For exposition, we pooled together deciles 1 and 2, deciles 3-5, deciles 6-8, and deciles 9-10. In panel A, we show the unadjusted growth rates in house prices. In panel B, we adjust the change in house prices within the census tract for the change in housing quality in the census tract over the period. See the text for details. All results are reported weighting the census tracts in the decile groupings by the number of owner-occupied housing units in the census tract. 